\title{
O FORMALISMO JURÍDICO EM HANS KELSEN: TENSÕES E LIMITES
}

\section{Caio Santiago Santos ${ }^{1}$}

\section{Resumo}

O objetivo deste trabalho é discutir tensões e limites no formalismo jurídico de Hans Kelsen. Trata-se de pesquisa teórica por meio da revisão bibliográfica de trabalhos do autor, não se limitando à obra Teoria Pura do Direito. Conclui-se que a sua proposta de "pureza metodológica" por vezes conflita com a "impureza" do objeto e da prática jurídica. De todo modo, apesar dos limites e tensões em Kelsen, aponta-se para a atualidade da proposta de uma ciência do direito com foco no estudo de normas jurídicas positivas.

Palavras-chave: Positivismo jurídico, Formalismo, Ciência do Direito, Kelsen, Decisão judicial.

\section{INTRODUÇÃO}

Os debates sobre conceito de direito e ciência do direito são da mais alta relevância. Entre outros motivos, esses debates influenciam a própria prática jurídica. A adoção, pelo profissional do direito, de uma ou outra determinada concepção sobre o direito e sobre o conhecimento jurídico tende a conformar a sua própria prática, em especial em relação à justificação de decisões judiciais. No Brasil, houve um certo predomínio do formalismo jurídico de Hans Kelsen até a década de 1980. Desde então, houve uma recepção e fortalecimento de autores posteriores e críticos a Kelsen, animando debates sobre o conceito do direito e a ciência do direito.

O objetivo deste trabalho é discutir tensões e limites na concepção de direito e de ciência do direito em Hans Kelsen. O formalismo jurídico, de modo geral, pode ter diversos significados e aparecer de distintas formas. Em Kelsen, o conceito de direito é formalista, uma vez que independe do conteúdo das normas jurídicas. Além

\footnotetext{
${ }^{1}$ Doutorando em Direito na Universidade de São Paulo, Área de Concentração "Filosofia e Teoria Geral do Direito". Pesquisador Visitante no Centro de Estudos Sociais da Universidade de Coimbra. E-mail: caio.santiago.santos@usp.br
} 
disso, e sobretudo, Kelsen propõe um formalismo metodológico para o estudo de normas jurídicas, com base na distinção entre plano do ser e plano do dever-ser: Essa distinção é realizada pela ciência do direito, não ocorrendo na prática jurídica em si. Ou seja, Kelsen não tem uma visão formalista sobre diversos aspectos da prática jurídica, como a decisão judicial, mas sim sobre a ciência do direito. Dessa forma, sustenta-se nesse trabalho que "pureza metodológica" pode por vezes conflitar com a "impureza" do objeto e da prática jurídica, o que gera algumas tensões e indica limites para sua metodologia.

Este trabalho utiliza como referência principal a própria obra de Kelsen, a partir da qual desenvolve uma pesquisa teórica. As referências a outros autores são feitas de forma secundária, seja para melhor delimitar as posições de Kelsen, seja para buscar identificar influências no seu pensamento. Este trabalho está dividido em três partes. Primeiro, apresenta-se a proposta de ciência do direito de Kelsen, ou seja, a sua proposta de "pureza metodológica". Segundo, aborda-se o seu conceito de direito. Terceiro, discutem-se algumas tensões e limites no formalismo jurídico de Kelsen.

\section{A CIÊNCIA DO DIREITO}

Em 1911, Hans Kelsen lança as bases para sua proposta de ciência do direito em dois trabalhos: Principais problemas na teoria do direito público e nas fronteiras dos métodos jurídico e sociológico. Kelsen inicia uma crítica que permanecerá ao longo da sua obra: a de que algumas teorias do direito confundem o método jurídico e o método sociológico. A proposta do autor é justamente desenvolver um método jurídico de estudo do direito, que seja autônomo em relação ao método sociológico.

Para Kelsen (2000a, p. 57), no texto Nas fronteiras dos métodos jurídico e sociológico, a ciência do direito [jurisprudence $]^{2}$ é uma disciplina normativa, e não explicativa, como a sociologia. Como tal, busca compreender normas jurídicas produzidas por autoridades que exercem o poder, ou seja, busca compreender o direito positivo. Ao contrário das disciplinas explicativas, a ciência do direito trabalha com afirmações de que algo "deve ser", o que é logicamente distinto de afirmar que algo "é". Afirmar que algo "ê" e que algo "deve ser" são formas distintas de pensamento. No entanto, a ciência do direito é normativa em "sentido derivado" [derivative sense] (KELSEN, 2000a, p. 58), uma vez que não produz normas, mas as estuda. De todo modo, o mais relevante é que a ciência do direito não busca explicar ocorrências ou eventos reais na sociedade e identificar relações de causalidade, como a sociologia.

Nesse sentido, Kelsen (2000a, p. 60) indica que algumas teorias cometem "erros metodológicos" de

\footnotetext{
${ }^{2}$ A expressão legal scholarship também é utilizada para designar a ciência do direito.
} 
tentar explicar eventos reais por meios normativos, produzindo uma "ficção". É o caso da "teoria do reconhecimento" de Ernst Rudolf Bierling, que sustenta a existência de estados psíquicos dos indivíduos de concordância com as normas, mas sem meios empíricos de pesquisa social. É o que ocorre também com a chamada "teoria orgânica do estado" que supõe uma "vontade comum” do povo, como um estado psíquico real, que seria o fundamento para o Estado (KELSEN, 2000a, p. 62). No entanto, para Kelsen tal ideia contrasta com as evidentes divisões sociais ${ }^{3}$. Encontra-se aqui, portanto, o eixo geral da crítica de Kelsen à teoria do direito público de então: a de confundir os métodos jurídico e sociológico, uma vez que tentava responder a problemas relacionados a eventos reais por meio normativos.

Enquanto disciplina normativa, a ciência do direito só pode responder a problemas normativos. Nesse sentido, alguns problemas não estão no seu campo, como o problema de fundamento de validade do direito positivo ou o das causas que levam indivíduos a obedecerem às normas. Tratam-se de questões próprias de outras disciplinas, a serem respondidas por outros métodos, que não o jurídico. Nesses casos, juristas devem respeitar e trabalhar com resultados produzidos por essas outras disciplinas, que em muitos casos podem até ser relevantes para a prática jurídica. Kelsen (2000a, p. 61) utiliza o exemplo da "vontade" [will], que costuma ser objeto de pesquisas de direito penal e de direito privado, como tema "que não pertence ao campo da ciência jurídica"4. Sobre esse tipo de problema, a ciência do direito pode no máximo oferecer uma resposta normativa, de por que as pessoas devem obedecer às normas, por exemplo.

Em 1915, Kelsen (2010) volta a enfatizar a diferença entre os métodos sociológico e jurídico, desta vez na sua crítica à obra Fundamentos da Sociologia do Direito de Eugen Ehrlich. Kelsen afirma que Ehrlich nega a possibilidade de uma ciência normativa, de modo que a única "verdadeira" e "científica" seria a explicativa. No entanto, existem para Kelsen duas formas igualmente viáveis para estudar o fenômeno jurídico. De um lado, a ciência do direito como disciplina normativa e dedutiva, tendo normas como objeto (no plano do dever-ser). De outro, como disciplina explicativa e indutiva, tendo fatos como objeto (no plano do ser). Embora por vezes ambas recebam o nome de "ciência do direito", o que pode causar confusão, não é admissível a confusão entre elas, o que gera um "sincretismo metodológico" (KELSEN, 2010, p. 5), erro no qual recairia Ehrlich. Portanto, cada disciplina utiliza um método e adota um objeto de estudo diferente. Nesse sentido, um estudo causal e empírico sobre comportamentos humanos só pode tecer afirmações no plano do ser, e nada sobre normas de dever-ser. Dessa forma, para Kelsen, Ehrlich comete o erro de extrair um dever-ser de um ser, o que não é logicamente possível. A qualidade de "jurídico" não é inerente aos fatos, sejam sociais ou psíquicos, mas conferidos por meio de normas

\footnotetext{
${ }^{3}$ Nesse sentido, Kelsen (2000a, p. 62) afirma: "One need not be a Marxist to consider a common will that psychically unites an entire people to be a phantom, given the deep class divisions that rend the people of a state who form a legal unity."
} 
jurídicas, para Kelsen.

Mais de uma década depois, no texto Formalismo jurídico e a teoria pura do direito de 1929, Kelsen não só continua na sua defesa da separação entre método sociológico e método jurídico, mas parece dar um passo além, ao afirmar que a ciência do direito deve ser formalista, tal como proposto pela sua teoria, que passa a receber o nome de Teoria Pura do Direito. Nesse texto, partindo de uma clara separação entre a produção de normas por autoridades (o que ocorre na prática jurídica) e a cognição dessas normas pela ciência, Kelsen afirma que o mérito da sua teoria é que fornece conceitos formais que permitem a apreensão de diferentes ordens jurídicas, independentemente do seu conteúdo específico. Isto porque sem conceitos formais, elaborados por uma teoria do direito, não é possível estudar uma ordem jurídica específicas ${ }^{5}$. Ou seja, a sua metodologia é formalista na medida em que permite estudar qualquer ordem jurídica, "separando forma e conteúdo no fenômeno do direito positivo" (KELSEN, 2000b, p. 77). Este caráter teorético, que não se confunde com a produção de normas, almeja realizar o ideal de objetividade do conhecimento científico ${ }^{6}$. Neste trabalho de 1929, Kelsen identifica um "sincretismo metodológico" desta vez nas teorias de Direito Natural, que deduzem e justificam o conteúdo de normas jurídicas a partir de conceitos científicos gerais. Essas teorias, para Kelsen (2000b, p. 79-80), são, na verdade, uma forma "mascarada" de fazer política, baseada na "ficção" de uma "vontade geral". No entanto, essa suposta "vontade geral", para Kelsen, nada mais é do que a expressão de interesses específicos. A ciência jurídica, para Kelsen, não deve ser fonte de direito positivo.

Na obra Teoria Pura do Direito, cuja primeira edição é de 1934 e a segunda de 19607, Kelsen reafirma, logo nas primeiras páginas, a autonomia do método jurídico. Deixa claro que a "pureza” refere-se à metodologia da ciência jurídica, e não ao direito em si. Dessa forma, Kelsen sugere que o direito é "impuro", ou seja, sofre influência da política e da economia. O que não é possível para ele é que essas influências alcancem também a ciência do direito. Nas suas palavras:

Quando a Teoria Pura empreende delimitar o conhecimento do Direito em face destas disciplinas [psicologia, sociologia, ética e teoria política], fá-lo não por ignorar ou, muito menos, por negar essa conexão, mas porque intenta evitar um sincretismo metodológico que

\footnotetext{
${ }^{4}$ Kelsen (2000a, p. 61) afirma: "The will is a fact of psychic life and investigating it the task of psychologists. To the extent he must operate with the concept of the will, the lawyer must be satisfied with the findings provided to him by psychology."

${ }^{5}$ É na obra Teoria Pura do Direito que Kelsen desenvolve de forma mais detida esses conceitos formais, tais como dever, direito subjetivo, responsabilidade e sanção, entre outros.

${ }^{6}$ Norberto Bobbio (2008, p. 97-99) afirma que Kelsen "estudou cuidadosamente o pensamento weberiano" e que "buscava os mesmos objetivos, no campo do Direito, e aí tendia, confiando na mesma inspiração fundamental que era a de separar pesquisa científica dos programas políticos, de impedir que os juízos de valor contaminassem a pureza da pesquisa." Ou seja, Kelsen foi influenciado pelo ideal de ciência avalorativa de Max Weber. Na obra Direito e Poder de 1992, Bobbio republica seus escritos sobre Kelsen e indica para a atualidade de algumas contribuições do autor.

${ }^{7}$ A tradução brasileira da primeira edição da Teoria Pura do Direitoé de 1939, momento a partir de que é possível supor que houve uma recepção mais intensa das ideias de Kelsen no Brasil. Em 1938 foi publicada uma tradução brasileira da obra Teoria Geral do Estado.
} 
obscurece a essência da ciência jurídica e dilui os limites que the são impostos pela natureza do seu objeto. (KELSEN, 2006, p. 1-2)

Kelsen dedica o terceiro capítulo da obra para sistematizar a sua proposta de ciência do direito. A expressão "Direito", afirma, por vezes pode ter uma ambiguidade no seu uso, uma vez que pode significar tanto um conjunto de normas jurídicas, quanto a disciplina que estuda essas normas jurídicas (KELSEN, 2006, p. 407) ${ }^{8}$. Essa ambiguidade é negativa, uma vez que pode reforçar a confusão entre a função das autoridades de elaborar normas jurídicas, e a função da ciência jurídica. Para Kelsen, ressalte-se, a ciência do direito não produz normas, mas descreve as normas jurídicas existentes. Por isso, as proposições científicas não estão sujeitas ao exame de validade ou invalidade, como as normas. Ao contrário, apenas podem ser verdadeiras, se descreverem corretamente as normas jurídicas existentes, ou falsas. Trata-se, portanto, de uma crítica à "jurisprudência tradicional" que sustenta que a ciência do direito pode também elaborar normas, tendo um caráter prescritivo sobre a conduta humana e gerando uma "confusão entre ciência jurídica e política do Direito" (KELSEN, 2006, p. $408)^{9}$.

Além da diferença do objeto da ciência do direito, que estuda normas jurídicas, das demais ciências, que estudam fatos sociais, o princípio lógico descritivo também é distinto. A ciência do direito trabalha com a imputação, enquanto as ciências sociais e naturais com a causalidade ${ }^{10}$. Esta descreve uma conexão entre dois fatos que independe da vontade humana. Ou seja, trata-se de uma ligação que praticamente sempre ocorre. Além disso, forma-se uma cadeia interminável de causa e efeito. Um fato social possui múltiplas causas os quais, por sua vez, também possuem cada qual causas diversas. $\mathrm{O}$ mesmo fato social também gera diversas consequências, os quais, por sua vez, também geram outras consequências, e assim sucessivamente. A causalidade, enquanto princípio explicativo da realidade social, pode ser sintetizada na seguinte fórmula: "se A é, então B é".

O princípio da imputação, utilizado pela ciência do direito, é distinto. Ele descreve uma ligação entre dois fatos produzida pela norma jurídica, ou seja, uma ligação normativa. Trata-se, portanto, de uma ligação que depende da vontade humana ${ }^{11}$. Ao contrário da causalidade, uma ligação normativa pode ou não se realizar efetivamente em determinado caso. E mesmo que a consequência prevista na norma para determinado fato não se

\footnotetext{
${ }^{8}$ Trata-se de referência à nota de rodapé 7 do terceiro capítulo.

${ }^{9}$ Referência à nota de rodapé 8 do terceiro capítulo.

${ }^{10}$ Para Kelsen (2006, p. 96), a "distinção [...] entre as mencionadas ciências sociais e as ciências naturais é, em todo caso, uma distinção apenas de grau e não de princípio", uma vez todas trabalham com o princípio da causalidade. E continua: "Uma distinção essencial existe apenas entre as ciências naturais e aquelas ciências sociais que interpretam a conduta recíproca dos homens, não segundo o princípio da causalidade, mas segundo o princípio da imputação."

${ }^{11}$ Em texto de 1950, intitulado Causalidade e imputação, Kelsen (2001, p. 324) afirma: "A ligação entre causa e efeito é independente do ato de um ser humano ou sobre-humano. Mas a ligação entre um delito e uma sanção jurídica é estabelecida por um ato, ou atos, de seres humanos, por um ato criador de Direito, isto é, um ato cujo significado é uma norma."
} 
realize, a conexão não deixa de existir ${ }^{12}$. Além disso, no princípio da imputação existe um ponto terminal: o fato social que gera a consequência jurídica não possui um vínculo normativo com fato anterior, ao mesmo tempo que a consequência jurídica não gera outra consequência normativa. A fórmula síntese do princípio da imputação, utilizado pela ciência do direito para descrever as normas jurídicas, é: "se A é, então B deve ser".

Kelsen ressalta que os princípios da coerência e da não-contradição não se aplicam diretamente às normas jurídicas, mas sim às proposições elaboradas pela ciência do direito que descrevem essas normas. As normas jurídicas se tornam um sistema coerente em razão da ciência do direito. Em outras palavras, a ciência do direito tem o dever de coerência e descreve as normas como se não houvesse contradição entre elas, resolvendo eventuais antinomias que, para a ciência do direito, são consideradas apenas "aparentes" (KELSEN, 2006, p. 229) ${ }^{13}$. Nesse sentido, uma norma jurídica posterior derroga a anterior com que tiver contradição, e uma norma especial derroga a geral. Além disso, uma norma só é válida se estiver em acordo com a norma superior. Em suma, essas são as linhas gerais do formalismo metodológico de Kelsen.

\section{O DIREITO}

O objeto da ciência do direito proposta por Kelsen, como afirmado no item anterior, são as normas jurídicas $^{14}$. A sua metodologia apresenta uma clara definição do que seja Direito, que está centrado na ideia de norma jurídica ${ }^{15}$. Dessa forma, a ciência do direito busca estudar as normas jurídicas, e não fatos ou eventos sociais, como a conduta humana, por exemplo. A ciência do direito pode, no máximo, oferecer uma "interpretação normativa" (KELSEN, 2006, p. 4) da conduta humana, isto é, se lícita ou ilícita.

Kelsen desenvolve o seu conceito de Direito na obra Teoria Pura do Direito, em especial no primeiro capítulo. Para ele, uma norma é sobretudo um comando, um ato de vontade de um indivíduo ou órgão sobre a conduta de outro indivíduo. No entanto, nem todo ato de vontade se torna uma norma jurídica. Um comando só se torna norma jurídica se estiver de acordo com outra norma jurídica superior. Dessa forma, Kelsen estabelece a diferença entre sentido subjetivo de um ato, vinculado à vontade do agente, e sentido objetivo do ato, o seu

\footnotetext{
${ }^{12}$ Em sentido semelhante, Herbert Hart afirma que "não existe ligação necessária entre a validade de alguma norma particular e sua eficácia” (HART, 2009, p. 133, grifo do autor). A obrigação decorrente de uma regra jurídica permanece mesmo que a conduta não seja efetivamente realizada pelo indivíduo.

${ }^{13}$ Referência ao quinto capítulo intitulado Dinâmica jurídica.

${ }^{14}$ Alf Ross (2000, p. 41), ao contrário, propõe que o foco da ciência do direito seja as decisões judiciais e não o conteúdo dos textos legais. Em crítica à Kelsen, cita o exemplo do estudo de um jogo de xadrez em que se deve observar a conduta efetiva dos jogadores e como estes utilizam as regras, e não as regras em si, dissociadas do fenômeno social do xadrez.

${ }^{15}$ Para Niklas Luhmann (2016), a teoria de Kelsen, entre outras, representa uma auto-observação feita pelo sistema jurídico. No entanto, a partir de uma observação externa ao sistema jurídico, Luhmann indica que a especificidade do sistema jurídico encontrase na função que desempenha para a sociedade: a generalização congruente de expectativas normativas.
} 
significado perante as normas jurídicas. A diferença entre o ato de um agente estatal cobrando impostos e o de um "salteador" cometendo crimes não está no sentido subjetivo de cada ato, mas sim no sentido objetivo, seja o exercício de uma competência jurídica, seja a prática de um ilícito penal que enseja uma sanção. Nesse sentido, assim afirma Kelsen:

'Dever-ser' é o sentido subjetivo de todo ato de vontade de um indivíduo que intencionalmente visa a conduta de outro. Porém, nem sempre um tal ato tem também objetivamente este sentido. Ora, somente quando esse ato tem também objetivamente o sentido de dever-ser é que designamos o dever-ser como 'norma'. A circunstância de o 'dever-ser' constituir também o sentido objetivo do ato exprime que a conduta a que o ato intencionalmente se dirige é considerada como obrigatória (válida), não apenas do ponto de vista do indivíduo que põe o ato, mas também do ponto de vista de um terceiro desinteressado [...] (KELSEN, 2006, p. 8)

Este é o sentido estrito de "dever-ser" em sentido estrito, como a prescrição de uma conduta. No entanto, Kelsen indica um sentido amplo, que abrange também uma permissão, ou seja, quando uma conduta é permitida, e uma atribuição de competência, ou seja, quando uma conduta é facultada. Dessa forma, na Teoria Pura do Direito Kelsen define o conceito de dever-ser como um ato humano direcionado a conduta de outra pessoa, no sentido de prescrição, permissão ou atribuição de poder. No entanto, uma norma jurídica não se confunde com o comando ou a vontade psíquica que a positivou, até mesmo porque estão em planos distintos seja do ser, seja do dever-ser ${ }^{16}$. Por exemplo, a existência de uma norma criada pelo Legislativo não depende mais da vontade deste após sua edição. Nas palavras de Kelsen:

A 'existência' de uma norma positiva, a sua vigência, é diferente da existência do ato de vontade de que ela é o sentido objetivo. A norma pode valer (ser vigente) quando o ato de vontade de que ela constitui o sentido já não existe. [...] É errôneo caracterizar a norma em geral e a norma jurídica em particular como 'vontade' ou 'comando' - do legislador ou do Estado -, quando por 'vontade' ou 'comando' se entenda o ato de vontade psíquica. (KELSEN, 2006, p. 11)

Outro aspecto fundamental no conceito de direito de Kelsen é a sanção. A ordem jurídica envolve necessariamente um momento de coação como uma reação a condutas humanas consideradas indesejadas. A aplicação desta sanção independe da vontade do destinatário, o qual normalmente a vislumbra como um mal. É por meio da sanção que a ordem jurídica regula a conduta humana. Na verdade, uma determinada conduta só é considerada prescrita para Kelsen (2006, p. 56) "quando a conduta oposta seja normada como pressuposto de um ato coercitivo que é dirigido contra os indivíduos que por tal forma se conduzam". Normas que contenham prescrições de conduta sem estabelecer algum vínculo com uma sanção para a conduta oposta, seja de forma direta, seja por meio de outra norma que contenha a sanção, são consideradas como "juridicamente irrelevantes" (KELSEN, 2006, p. 59). Para Kelsen, tratam-se de normas válidas, mas sem relevância para regular a conduta humana.

\footnotetext{
${ }^{16}$ Tércio Sampaio Ferraz Jr. (2003, p. 100-101) denomina essa concepção de norma em Kelsen como "norma-proposição”.
} 
A sanção jurídica é o que distingue a ordem jurídica de outras ordens sociais, segundo Kelsen. $\mathrm{Na}$ verdade, ordens sociais como a religião e a moral possuem sanções próprias de natureza psíquica, exercidas por meio de uma pressão social difusa, que também orientam a conduta humana. Por vezes, admite Kelsen, essas sanções psíquicas da moral e da religião podem até gozar de uma eficácia maior do que as sanções da ordem jurídica. Mesmo assim, é o caráter específico da sanção da ordem jurídica, que pode envolver violência física, que a distingue de outras ordens sociais:

Como ordem coativa, o Direito distingue-se de outras ordens sociais. $\mathrm{O}$ momento coação, isto é, a circunstância de que o ato estatuído pela ordem como consequência de uma situação de fato considerada socialmente prejudicial deve ser executado mesmo contra a vontade da pessoa atingida e - em caso de resistência - mediante o emprego da força física, é o critério decisivo. (KELSEN, 2006, p. 37)

A definição de norma jurídica em Kelsen independe do conteúdo da norma, se considerada justa ou injusta, seja pela sociedade, seja por quem a estuda. Ou seja, o valor justiça não é um critério constitutivo do conceito de direito em Kelsen, em razão do seu caráter relativo e não universal ${ }^{17}$. Dessa forma, para Kelsen é possível utilizar um critério exclusivamente formal para identificar uma norma jurídica, independente da concordância ou não com o seu conteúdo. Nesse sentido, Kelsen afirma:

Uma ordem jurídica pode ser julgada como injusta do ponto de vista de uma determinada norma de Justiça. O fato, porém, de o conteúdo de uma ordem coercitiva eficaz poder ser julgado como injusto, não constitui de qualquer forma um fundamento para não considerar como válida essa ordem coercitiva. (KELSEN, 2006, p. 55)

Em suma, para Kelsen é o Direito como ordem coativa que regula a conduta humana, independente do seu conteúdo específico, que é o objeto da ciência do direito ${ }^{18}$.

\section{TENSÕES E LIMITES NA METODOLOGIA DE KELSEN}

A proposta de ciência do direito de Kelsen apresenta alguns limites e pontos de tensão. Alguns são indicadas expressamente pelo próprio autor. É o que acontece no prefácio da primeira edição da Teoria Pura do Direito, quando afirma que, embora o seu postulado metodológico não possa ser posto em dúvida, é possível questionar até que ponto é realizável. Indicando para uma relação entre teoria e o então contexto de forte polarização política, afirma: "O ideal de uma ciência objetiva do Direito e do Estado só num período de equilíbrio

\footnotetext{
${ }^{17}$ A definição de norma jurídica de Kelsen é diferente de autores como Ronald Dworkin, que admite que princípios morais sejam considerados normas jurídicas. Nesse sentido, afirma: "A origem desses princípios enquanto princípios jurídicos não se encontra na decisão particular de um poder legislativo ou tribunal, mas na compreensão do que é apropriado, desenvolvida pelos membros da profissão e pelo público ao longo do tempo" (DWORKIN, 2010, p. 64). Ou seja, um princípio está relacionado com "as práticas morais contemporâneas" (DWORKIN, 2010, p. 65).

18 "[...] o conhecimento jurídico dirige-se a estas normas que possuem o caráter de normas jurídicas e conferem a determinados fatos o caráter de atos jurídicos (ou antijurídicos). Na verdade, o Direito, que constitui o objeto deste conhecimento, é uma ordem normativa da conduta humana, ou seja, um sistema de normas que regulam o comportamento humano." (KELSEN, 2006, p. 5).
} 
social pode aspirar a um reconhecimento generalizado" (KELSEN, 2006, p. XIV). Ou seja, uma primeira tensão parece ser que a viabilidade de sua proposta de ciência do direito depende de determinadas condições sociais, a serem analisadas por uma sociologia do conhecimento jurídico. A seguir são destacados três outros aspectos da sua obra.

\section{O fundamento da ordem jurídica}

Uma tensão não indicada expressamente pelo autor, mas que pode ser identificada na leitura da sua obra, é a "norma fundamental". Esta é a forma pela qual Kelsen lida com o problema do fundamento da ordem jurídica. As normas jurídicas possuem uma relação hierárquica entre si, formando uma estrutura escalonada em que a Constituição está no topo. Vislumbra-se em Kelsen, dessa forma, um importante papel atribuído à Constituição. A validade da Constituição, por sua vez, repousaria na norma fundamental que, ao contrário das normas positivas, possui uma natureza lógica e transcendental. Ou seja, não é uma norma posta, que corresponde a um ato de vontade, mas sim uma pressuposição operada pela ciência do direito para ter condições para estudar as normas positivas. Como na teoria de Kelsen a validade de uma norma só pode decorrer de outra norma superior, pressupõe-se então a norma fundamental para conferir validade à Constituição. No entanto, em que momento é possível pressupor essa norma fundamental?

A resposta de Kelsen é que a pressuposição da norma fundamental depende de uma "eficácia global" da ordem jurídica, ou seja, de que em geral seja observada pelos indivíduos e aplicada pelos tribunais. Em caso de conflito entre uma ordem estatal, de um lado, e a ordem de um "bando de salteadores" no interior do território estatal, de outro, pressupõe-se uma norma fundamental para aquela ordem que lograr maior eficácia (KELSEN, 2006, p. 48). Se o "bando de salteadores" lograr sobrepor, em eficácia, suas normas às normas estatais, constitui-se uma nova ordem jurídica. É o que acontece também, segundo Kelsen, para o caso de um navio pirata em alto mar. No interior do navio, a ordem jurídica é a pirata uma vez que possui eficácia global neste espaço, ocorrendo a pressuposição de uma norma fundamental (KELSEN, 2006, p. 53).

No entanto, e aqui está a tensão, ao mesmo tempo em que a pressuposição da norma fundamental depende da eficácia global da ordem jurídica, a ciência do direito não analisa os problemas de eficácia, uma vez estes estão no plano do ser. Analisar com base no princípio da causalidade os fatores que contribuem para a eficácia global de uma ordem jurídica, da qual depende a pressuposição da norma fundamental, foge das possibilidades da ciência do direito de Kelsen. Dessa forma, o fundamento da ordem jurídica não é respondido pela ciência do direito, uma vez que envolve fatores extranormativos, como a política e a economia. Kelsen reconhece a relevância da eficácia global da ordem jurídica para a ciência do direito, mas não se propõe a estudá-la. 
No texto de 1911, Nas fronteiras dos métodos jurídico e sociológico, Kelsen já indicava que enquanto disciplina normativa, a ciência do direito só pode responder a problemas normativos. Problemas que não são normativos, como o do fundamento da ordem jurídica, devem ser resolvidos por outras disciplinas. A ciência do direito pode no máximo oferecer uma resposta normativa, de por que as pessoas devem obedecer às normas. É o que parece ser a "norma fundamental" que Kelsen desenvolve na Teoria Pura do Direito: uma tentativa de resposta normativa a um problema não-normativo.

\section{A distinção entre ser e dever-ser}

Na proposta de Kelsen, a distinção entre sere dever-seré realizada pela ciência do direito. É a ciência que busca isolar as normas jurídicas do seu contexto de produção e das suas condições de eficácia. Na realidade social, Kelsen reconhece que diversos fatores políticos e econômicos influenciam a produção de normas, seja a promulgação de uma lei pelo Legislativo, seja o juiz ao proferir uma sentença. Além disso, normas igualmente válidas podem gozar de diferentes níveis de eficácia entre si, em razão também de fatores extranormativos. É isso que significa afirmar que a pureza está na teoria, e não no objeto ou na prática jurídica.

No entanto, até que ponto essa distinção entre ser e dever-ser é realizável? Com base na experiência brasileira, é possível pensar dois exemplos para refletir sobre essa questão. Tanto no período de 1964 a 1985, um regime autoritário, quanto no subsequente, um regime democrático, foram produzidas normas jurídicas. De modo geral, as normas de ambos períodos são consideradas válidas. Mas é possível realmente separar a norma jurídica do órgão de poder que a produziu? Uma norma produzida durante o regime militar, seja por uma junta militar, seja pelo Congresso eleito de forma não-democrática e que tinha restrições quanto à sua independência, tem evidentes diferenças em relação a uma norma produzida pós-1988, por um Congresso eleito com base em sufrágio universal. Mas, do ponto de vista da ciência do direito de Kelsen, todas são normas igualmente válidas, produzidas em regime autoritário ou em regime democrático, se estiverem de acordo com a Constituição vigente.

Um segundo exemplo é possível vislumbrar nas decisões judiciais proferidas cotidianamente por inúmeros juízes. Como Kelsen afirma, a decisão judicial é um ato de vontade em que o magistrado, em geral, escolhe uma das opções possíveis no âmbito de uma moldura elaborada pela ciência jurídica. Essa moldura pode ser maior ou menor a depender do caso, mas a margem de escolha em geral persiste. Nesse sentido, até que ponto é possível realmente separar uma sentença, norma jurídica individual e concreta, do juiz que a proferiu? A depender dos valores e opiniões políticas de um magistrado, a decisão judicial pode variar, sugere Kelsen. Não poderia um advogado ao interpor uma apelação incorporar nas suas razões críticas às opiniões políticas e aos valores do magistrado e indicar como elas influenciaram a sentença? 
A distinção entre norma jurídica, no plano do dever-ser, e fato social, no plano do ser, é sem dúvida fundamental para formar um conhecimento sobre normas jurídicas, que contribua para a decisão de conflitos sociais com base nessas normas. Ou seja, um conhecimento que forneça as bases para uma prática judicial orientada pelo direito positivo ${ }^{19}$. No entanto, esse conhecimento possui evidentes limites. Sobretudo, esse conhecimento é insuficiente para explicar o fenômeno jurídico nos seus diversos aspectos, como a relação entre diferentes contextos sociais e a produção normativa, e os fatores pelos quais uma norma é mais eficaz do que outra. Nesse sentido, Kelsen reconhece a relevância da sociologia do direito, que utiliza o princípio da causalidade para analisar fatos relacionados ao fenômeno jurídico, embora a distinga radicalmente da sua proposta de ciência do direito ${ }^{20}$.

Enfim, a operacionalização pela ciência do direito da diferença entre ser e dever-ser torna-se mais justificável ao se deixar claro sua utilidade e ao mesmo tempo seus limites. O próprio Kelsen (2006, p. 117), ao responder a objeção de que a separação entre norma e ato de vontade que a produziu seria uma "ilusão", advoga pela clareza "crítica" no uso do seu método.

\section{A decisão judicial}

Como afirmado, o formalismo de Kelsen não se reflete na sua visão sobre a prática jurídica e, em especial, sobre a decisão judicial. No texto de 1929, Formalismo jurídico e a teoria pura do direito, Kelsen (2000b, p. 82) afirma que, incorporando uma tese da "Escola de Direito Livre" [School of Free Law], a aplicação do direito é uma produção de normas tanto quanto a edição de leis. Nesse sentido, a decisão judicial é um ato de vontade, e não de conhecimento, tanto quanto a decisão do Legislativo de promulgar ou não uma lei. Nesse sentido, da mesma forma que não cabe à ciência afirmar qual deve ser o conteúdo de uma lei, ou seja, a norma que o parlamento deve elaborar, também não cabe à ciência apontar qual decisão judicial é a mais correta. É uma "ilusão" (KELSEN, 2000b, p. 82) a ideia de que só existe uma decisão correta ou de que o juiz está rigidamente adstrito à lei. A lei fornece apenas uma moldura para a decisão judicial, competindo ao juiz preenchê-la. Neste texto Kelsen deixa claro que não desenvolveu propriamente uma teoria da decisão judicial.

Na obra Teoria Pura do Direito, o capítulo oitavo é dedicado à interpretação, parte em que sustenta que

\footnotetext{
${ }^{19}$ Em relação ao direito estatal, Boaventura de Sousa Santos (2014, p. 38) afirmar que sua "atuação deriva não só da lógica normativo-constitucional que subjaz à filosofia política do Estado liberal como, mais imediatamente, do vasto arsenal do formalismo jurídico em geral e do formalismo processual em especial [...].”

${ }^{20}$ Esses limites e tensões em Kelsen indicam para a necessidade de o ensino jurídico não seguir apenas a metodologia kelseniana. Embora possa ter um papel central, o formalismo jurídico deve ser complementado por outros conhecimentos, como os da sociologia do direito. Sobre a sociologia do direito, Kelsen (2006, p. 113) sustenta que estuda "fatos da ordem do ser" como "fenômenos paralelos" ao próprio Direito.
} 
o papel da ciência é delimitar a moldura em torno de uma norma jurídica, no interior da qual existem múltiplas possibilidades de decisão judicial. Dessa forma, a moldura pode ser maior ou menor, a depender do caso e conforme o debate científico. Mas, em última instância, a decisão será um produto do ato da vontade do magistrado. Kelsen reconhece que até mesmo uma decisão fora da moldura é uma norma, embora possa ser depois anulada.

Este ponto pode ser considerado como um limite, na medida em que não enfrenta de forma detida, como outros aspectos da sua obra, algo tão relevante para a prática jurídica quanto a decisão judicial. Embora Kelsen sustente uma distinção entre teoria do direito e teoria da interpretação, é possível desenvolver algumas conexões entre ambas. A mais importante é que Kelsen sugere que a decisão judicial só pode ser justificada por meio de normas ${ }^{21}$. Ou seja, a moldura é construída em torno de uma norma jurídica, e não de um princípio moral, por exemplo. É a norma jurídica positiva que deve ser objeto de interpretação, para Kelsen, e não um princípio moral. Dessa forma, a teoria do direito de Kelsen fornece contribuições para uma teoria da interpretação de normas jurídicas positivas.

Além disso, a ideia de moldura representa algum limite para a decisão judicial, ainda que no plano da ciência. Decisões judiciais podem ser eventualmente identificadas pela ciência como estando fora da moldura, ou seja, como normas jurídicas individuais e concretas em desacordo com as normas gerais e abstratas superiores. Nesses casos, a decisão judicial seria um mero ato de vontade, sem qualquer justificativa possível em parâmetros normativos, equiparando-se a uma decisão política própria do Legislativo. Esse tipo de decisão tende a prejudicar a legitimidade do Judiciário e seu papel social de resolver conflitos sociais com base em normas jurídicas. Ou seja, embora a decisão judicial seja um ato de vontade para Kelsen, ela ocorre dentro de parâmetros fornecidos pelo direito positivo. No entanto, e aqui está um limite da sua ciência do direito, se em determinada situação ocorrem muitas decisões fora da moldura, Kelsen não fornece parâmetros para identificar por queisso acontece.

\section{CONSIDERAÇÕES FINAIS}

Nos trabalhos de Kelsen ora analisados, situados entre 1911 e 1960, não ocorre rupturas no seu pensamento. O sentido geral é de desenvolvimento e de acréscimos às suas ideias iniciais. A proposta de Kelsen foi sobretudo desenvolver uma ciência do direito cujo foco resida no estudo de normas jurídicas positivas, independentemente do seu conteúdo específico. O ideal de objetividade proposto pelo autor permite que os debates na ciência do direito não sejam apenas um mero reflexo de debates puramente políticos, como os que

\footnotetext{
${ }^{21}$ Em sentido semelhante, sobre o "processo de justificação", conferir Shecaira e Struchiner (2016, p. 155).
} 
ocorrem no Congresso. A viabilidade dessa ciência do direito parece depender de alguns fatores extranormativos, como a estabilidade das relações de poder que produzem as normas jurídicas. Em contextos de crise política, é possível que as normas percam seu caráter geral e abstrato e decisões judiciais fora da moldura se tornem mais frequentes.

De todo modo, é possível identificar contribuições de Kelsen para alguns debates contemporâneos na teoria do direito. A produção de um conhecimento como proposto por Kelsen tende a contribuir para que o Judiciário decida conflitos sociais com base em normas jurídicas, e não em princípios morais ou valores econômicos, por exemplo. Esse conhecimento sobre normas é relevante em contextos democráticos, em que a norma jurídica é produto de uma deliberação democrática. Dessa forma, a ciência do direito como proposto por Kelsen pode contribuir para afirmar decisões democráticas no Judiciário e assim concretizar direitos constitucionais. Uma parte das críticas a Kelsen durante o regime militar brasileiro pode ter confundido a crítica a Kelsen com a crítica aos autores que fizeram sua recepção no Brasil ou com o próprio regime militar e sua própria legislação autoritária ${ }^{22}$. Trata-se de campo ainda passível de desenvolvimento, sobre os efeitos politicamente conservadores ou progressistas da recepção da sua obra no Brasil, na esteira de uma sociologia do conhecimento jurídico.

No entanto, identificar aspectos atuais em Kelsen não significa desconsiderar limites e tensões na obra de Kelsen. É o caso, como demonstrado, da ausência de uma clara teoria da interpretação, ainda que para Kelsen é a norma positiva que deva ser objeto de interpretação. Além disso, outros aspectos da sua obra, desenvolvida na primeira metade do século XX, podem ser passíveis de atualização. A título de exemplo, é o caso dos direitos sociais, que só ganharam mais expressividade no pós-segunda guerra mundial. A definição de norma jurídica em Kelsen parece ter como referência a regulação de comportamento de indivíduos, e não o desenvolvimento de políticas públicas. Talvez seja possível fornecer desenvolvimentos e atualizações teóricas a alguns desses pontos, a partir dos próprios pressupostos de Kelsen. Ou então, é possível desenvolver outras propostas de formalismo jurídico que também tenham como foco o estudo de normas jurídicas positivas, mas com base em outros fundamentos e pressupostos que não os de Kelsen.

Em suma, a obra de Hans Kelsen contribui para que a ciência do direito tenha como foco o estudo de normas, especialmente relevante quando elaboradas em contextos democráticos. Embora existam tensões e limites na sua teoria, Kelsen continua a ser referência fundamental para uma ciência do direito que descreva normas e que contribua para práticas judiciais orientadas pelo direito positivo.

\footnotetext{
${ }^{22}$ No texto Kelsen, o positivismo e o ensino do direito nos anos 70 de 2008, Celso Campilongo (2011, p. 43) critica a recepção de Kelsen realizada no Brasil ao afirmar: "Salvo raras exceções, o que prevaleceu nos anos 70 foi a vulgata kelseniana ou a utilização do
} 


\title{
LEGAL FORMALISM IN HANS KELSEN: TENSIONS AND LIMITS
}

\begin{abstract}
The objective of this paper is to discuss the tensions and limits in Hans Kelsen's legal formalism. The research method is a bibliographical review of the author's works, not limited to the Pure Theory of Law. This paper concludes that his proposal of a "methodological purity" sometimes conflicts with the "impurity" of the object and of legal practice. However, despite limits and tensions in Kelsen, this paper points to the contemporary relevance of a legal method focused on the study of positive legal norms.
\end{abstract}

Keywords: Legal positivism, Formalism, Jurisprudence, Kelsen, Judicial decision.

\section{REFERENCIAS}

BOBBIO, Noberto. Direito e poder. Tradução Nilson Moulin. São Paulo: Editora UNESP, 2008. [1992]

CAMPILONGO, Celso. Direito e Diferenciação Social. São Paulo: Saraiva, 2011.

DWORKIN, Ronald. Levando os direitos a sério. 3. ed. São Paulo: Martins Fontes, 2010. [1977]

EHRLICH, Eugen. Fundamentos da Sociologia do Direito. Tradução René Ernani Gertz. Brasília: Editora da UnB, 1986. [1912]

FERRAZ JR., Tércio Sampaio. Introdução ao Estudo do Direito: técnica, decisão, dominação. 4. ed. São Paulo: Atlas, 2003.

HART, Herbert. O Conceito de Direito. São Paulo: Martins Fontes, 2009. [1961]

KELSEN, Hans. On the borders between legal and sociological method. In: JACOBSON, Arthur; SCHLINK,

positivismo para legitimar elementos formalistas pré-existentes na cultura jurídica brasileira, como os formalismos da "Escola da Exegese' e da 'Jurisprudência dos Conceitos'” 
Bernhard (Eds.). Weimar: a jurisprudence of crisis. Berkley: University of California Press, 2000a, p. 57-63. [1911] Una "fondazione" della sociologia del diritto. In: FEBBRAJO, Alberto (Ed.). Verso un concetto sociologico di diritto. Milano: Giuffrè, 2010, p. 3-50. [1915]

Legal formalism and the pure theory of law. In: JACOBSON, Arthur; SCHLINK, Bernhard (Eds.).

Weimar: a jurisprudence of crisis. Berkley: University of California Press, 2000b, p. 76-83. [1929]

Teoria Geral do Estado. São Paulo: Saraiva, 1938. [1925]

Teoria Pura do Direito. Tradução de Fernando de Miranda. São Paulo: Saraiva, 1939. [1934]

Causalidade e Imputação. In: O que é justiça? 3. ed. São Paulo: Martins Fontes, 2001. [1950]

Teoria Pura do Direito. Tradução João Baptista Machado. 7. ed. São Paulo: Martins Fontes, 2006. [1960]

LUHMANN, Niklas. O Direito da Sociedade. São Paulo: Martins Fontes, 2016. [1993]

ROSS, Alf. Direito e Justiça. Bauru: Edipro, 2000. [1959]

SANTOS, Boaventura de Sousa. O Direito dos Oprimidos. São Paulo: Cortez, 2014.

SHECAIRA, Fábio; STRUCHINER, Noel. Teoria da argumentação jurídica. Rio de Janeiro: Contraponto, 2016.

Trabalho enviado em 08 de maio de 2018

Aceito em 31 de julho de 2018 